\title{
Knowledge and Attitudes about Schizophrenia among Employers in Japan
}

\author{
Hatsumi Yoshii ${ }^{1}$, Norika Mitsunaga ${ }^{1} \&$ Hidemitsu Saito ${ }^{1,2}$ \\ ${ }^{1}$ Health Sciences, Tohoku University Graduate School of Medicine, Sendai, Japan \\ ${ }^{2}$ Midorigaoka Hospital, Shiogama, Japan \\ Correspondence: Hatsumi Yoshii, Health Sciences, Tohoku University Graduate School of Medicine, 2-1 \\ Seiryo-machi, Aoba-ku, Sendai, Miyagi, Japan. Tel: 81-22-717-7954. E-mail: hatsumi@med.tohoku.ac.jp
}

Received: November 6, 2017 Accepted: December 19, 2017 Online Published: December 22, 2017

doi:10.5539/gjhs.v10n2p60

URL: https://doi.org/10.5539/gjhs.v10n2p60

\begin{abstract}
Purpose: A high percentage of schizophrenia patients cannot find work. If these patients are to find long-term employment, it is essential that employers understand schizophrenia. Therefore, this study aimed to assess knowledge and attitudes about schizophrenia among employers in Japan.

Methods: A total of 1877 executives were recruited from private companies to examine knowledge and attitudes about schizophrenia, awareness of employment support, and likelihood of hiring schizophrenic patients. Higher scores indicated greater knowledge and/or higher levels of stigma.

Results: Small-scale entrepreneurs were significantly less likely to believe that they might be able to employ a schizophrenia patient. They tended to regard mentally ill people, including schizophrenia patients, as dangerous, despite having little or no contact with them. Basic knowledge of schizophrenia was significantly higher $(\mathrm{p}=0.001)$ and average scores on a number of attitude measures significantly lower $(p=0.001)$ for employers who said they might employ people with schizophrenia than those that didn't. More than $83.5 \%$ of respondents were unaware of support available for people with mental illnesses. Half expressed desire for support from outside agencies in hiring and ongoing employment of people with schizophrenia.

Conclusions: This study identified a particular group of employers who were very unlikely to employ anyone with schizophrenia. This might enable targeted interventions to change attitudes among this group. Also found was a widespread lack of knowledge of support available for employers and employees, suggesting that more public information about this may be helpful in increasing employment among those with mental health problems.
\end{abstract}

Keywords: attitudes, employment, knowledge, schizophrenia

\section{Introduction}

There is a relatively low rate of employment among those with a mental illness in Japan. As of 2015, the percentage of individuals with a mental illness who have been employed has been considerably lower than the percentage of employed individuals with physical and learning disabilities (Cabinet Office, Government of Japan, 2013; Ministry of Health, Labour and Welfare, 2017). A mere 1.15\% of individuals with a mental illness have been working in private enterprises employing more than 50 workers, compared with $8.99 \%$ and $23.84 \%$ of individuals with physical or learning disabilities (Cabinet Office, Government of Japan, 2013; Ministry of Health, Labour and Welfare, 2017). A previous study, however, found that a larger proportion of mentally ill people than those with physical or learning disorders wished to work (Ali, Schur, \& Blanck, 2011). One study found that of mentally ill jobseekers visiting public employment security offices for advice, about half had schizophrenia in 2016 (Ministry of Health, Labour and Welfare, Dec 10, 2017). Schizophrenia is characterized by auditory hallucinations, delusion of passivity, delusional perception, thought echo, and thought interference (Puri, Hall, \& Ho, 2014). In total, 77.3\% of schizophrenia outpatients have been found to be without work, with $32.6 \%$ of these outpatients citing the reason for this as "cannot find work" (National Institute of Vocational Rehabilitation, 2010). These figures suggest that people with schizophrenia are eager to work but find it difficult to join the labor market. In Los Angeles, after sorting by type of disease, Liberman (1998) found that 40\% of unipolar depressive patients and $50 \%$ of drug-addicted patients participated in competitive employment. By contrast, $12 \%$ or fewer patients with schizophrenia or bipolar conditions did participate in competitive employment. Chronic mental illness is 
associated with high indirect costs because of unemployment and loss of productivity (Ho, Mak, Chua, Ho, \& Mak, 2013).

Since Japan ratified the Convention on the Rights of Persons with Disabilities in 2013, there has been a requirement to "recognize the right of persons with disabilities to work, on an equal basis with others" (Ministry of Foreign Affairs of Japan, 2017). To safeguard and promote the realization of this right, society must (1) "prohibit discrimination on the basis of disability with regard to all matters concerning all forms of employment"; (2) "protect the rights of persons with disabilities, on an equal basis with others, to just and favourable conditions of work"; and (3) "ensure that reasonable accommodation is provided to persons with disabilities in the workplace" (Ministry of Foreign Affairs of Japan, 2017). Previous studies have examined employers' attitudes toward employing those with mental disabilities or illnesses (Hand \& Tryssenaar, 2006; Olshansky, Grob \& Malamud, 1958; Ozawa \& Yaeda, 2007; Tse, 2004) and reported that they may be negative. Indeed, employers tend not to hire those with a mental illness or disability, even if they are prepared to hire those with a physical disability (Corrigan et al, 2008). Such studies have emphasized the need for employers to change their negative attitudes toward employing those with a mental illness. Employers who had previous experience hiring people with a mental disability were found to be more willing to employ such individuals again in the future (Dalgin \& Bellini, 2008; Dightman \& Marks, 1968). It is therefore important for employers to be encouraged to start the process of considering people with mental disabilities or illnesses as potential employees. To date, however, few studies have investigated intentions to hire schizophrenic patients or even knowledge and attitudes about schizophrenia among employers.

In a competitive business environment, companies need to pursue profits. Therefore, they need employment support measures if they are to employ people with mental illnesses. Employment support may have two components: support for mentally ill employees and support for employers. It is necessary to consider what type of employment support employers believe would be effective in promoting greater employment of schizophrenic patients. Therefore, the purpose of this study was to assess knowledge and attitudes about schizophrenia among employers in Japan. The results of this study could be used to develop employment strategies to help people with schizophrenia join or rejoin the job market.

\section{Methods}

\subsection{Participants}

The participants were all registered in a large database of 2,300,000 candidates administered by a private Japanese company specializing in questionnaire research. We screened participants to extract a list of those from private companies who were aged 20 years or older and who had agreed to answer questions about their own or family members' mental health issues. The authors drew a stratified random sample, with gender, region, and company size as stratification variables, to obtain a final sample of 1877 employers (senior advisors/presidents, directors, or branch managers/section chiefs). All participants completed a questionnaire covering their personal characteristics and their knowledge of and views on schizophrenia, including the Social Distance Scale-Japanese version and other test scales. Participants used a web-based questionnaire-answering system provided by the survey company. The research was consistent with the principles outlined in the Helsinki Declaration for the ethical conduct of human research. The medical ethics committee of Tohoku University approved the study. Informed consent (web-based) was obtained from all participants prior to participation.

\subsection{Questionnaire}

All participants used a web-based questionnaire-answering system provided by the survey company. The questionnaire consisted of eight sections.

\subsubsection{Section 1}

Section 1 collected respondents' demographic information.

\subsubsection{Section 2}

Section 2 consisted of 14 true/false items on basic knowledge of schizophrenia that were developed for this study. The items addressed the causes, symptoms, incidence rate, and treatment of schizophrenia. This questionnaire, the Basic Knowledge of Schizophrenia scale (BKS), was a revised version of that used by Yoshii and colleagues (Yoshii, Watanabe, Kitamura, Chen, \& Akazawa, 2011) with parents of junior high and high school students in Japan. To obtain the total BKS score, one point was added for each correct answer. Higher scores indicate greater knowledge. 


\subsubsection{Section 3}

Section 3 examined knowledge of mental illness and disabilities. We used the 20-item/three-option Knowledge of Illness and Drugs Inventory (KIDI) scale (Maeda, Ochiai, Renri, Aga, \& Mukasa, 1994) (Cronbach's $\alpha=0.69$ ). For each question, one point was added for a correct answer. The total score was then multiplied by five to obtain the final KIDI score. Higher scores indicate greater knowledge.

\subsubsection{Section 4}

Section 4 examined social distance from schizophrenia. It was based on the Social Distance Scale-Japanese version (SDSJ), which was adapted from Whatley's (1959) scale (Cronbach's $\alpha=0.849$ ). This scale consists of eight questions graded using a four-point Likert scale ( $0-3$ points), with higher scores representing increased social distance.

\subsubsection{Section 5}

Section 5 examined social distance from mental illness and disability in the workplace. The Workplace Social Distance Scale (WSDS) (Yoshii, Mandai, Saito \& Akazawa, 2015) was created by modifying the eight SDSJ items (Cronbach's $\alpha=0.753$ ). The WSDS, like the SDSJ, is an eight-item self-report inventory with a total score ranging from 0 to 24 points.

\subsubsection{Section 6}

Section 6 examined stigma toward mental disorder. We employed Link's (1987) Devaluation-Discrimination Measure (DDM), which uses a four-point Likert scale ("strongly agree" $=4$, "tend to agree" $=3$, "tend to disagree" $=3$, and "strongly disagree" $=1)($ Cronbach's $\alpha=0.85)$. A higher score indicates greater stigma.

\subsubsection{Section 7}

Section 7 asked about participants' awareness of employment support, with responses of either "yes" or "no".

\subsubsection{Section 8}

Finally, Section 8 examined the possibility of hiring schizophrenic patients (positive about the possibility, no possibility of employment, undecided).

\subsection{Statistical Analysis}

All analyses were performed using IBM SPSS Statistics for Windows version 20.0 (Armonk, NY USA: IBM Corp.). We used Pearson's chi-square test and the Kruskal-Wallis test of variance to compare the test distribution of the participants' extraneous factors and their willingness to consider employing schizophrenia patients. One-way analysis of variance was used to compare distribution of scores and willingness to consider employment. All statistical tests were two-tailed, and statistical significance was defined as $\mathrm{p}<0.05$.

\section{Results}

\subsection{Participant Characteristics}

There were 1877 respondents (1742 men; 135 women), with 734 in their 50s and 727 in their 40s. In total, 1100 respondents had completed university; 438 worked in manufacturing, and 391 worked in retail trade or financial insurance. The participants included 1017 branch managers (section chiefs), 541 senior advisors (presidents), and 319 directors. A total of 544 had worked for less than 10 years, 571 for $10-20$ years, 518 for $20-30$ years, and 244 for longer than 30 years. A total of 304 participants rated their achievements as good, 911 as "so-so," and 473 as bad.

\subsection{Employer Attitudes to Schizophrenia}

Participants were invited to select one of three options: being positive about the possibility of hiring schizophrenic patients $(n=390 ; 20.8 \%)$; seeing no possibility of hiring such people $(n=492 ; 26.2 \%)$; and being undecided $(n=$ 995; 53\%). The results of univariate analyses for the characteristics of employers exhibiting these three attitudes are shown in Table 1. When the three groups were compared, the significant factors (Pearson's chi-square or Kruskal-Wallis test, $\mathrm{p}<0.05$ ) were job description, sales results, company size, number of employees, length of service, previous employment of people with a mental illness or disability, familiarity with people with a mental illness or disability, clinical history of time in a psychiatric ward, having colleagues with mental disabilities, regarding mentally ill or disabled people as dangerous, having colleagues with schizophrenia, and regarding schizophrenia patients as dangerous. Respondents who were negative about employment were more likely to be branch managers/section chiefs, work for a small company, have moderate sales results, manage nine or fewer staff members, have a length of service of less than 10 years, have never employed anyone with a mental illness or 
disability in the past, be unfamiliar with mental illness or disability, have spent no time in a psychiatric ward themselves, have no colleagues with mental disabilities and/or schizophrenia, and view those with mental disabilities and/or schizophrenia as dangerous.

Table 1. Attitudes toward hiring schizophrenic patients among participants $(N=1877)$

\begin{tabular}{|c|c|c|c|c|c|c|c|c|}
\hline & \multirow{2}{*}{$\begin{array}{l}\text { Total } \\
n\end{array}$} & \multicolumn{2}{|c|}{$\begin{array}{l}\text { Positive about possibility of } \\
\text { employment }(n=390 \\
20.8 \%)\end{array}$} & \multicolumn{2}{|c|}{$\begin{array}{l}\text { No possibility of } \\
\text { employment }(n=492, \\
26.2 \%)\end{array}$} & \multicolumn{2}{|c|}{$\begin{array}{l}\text { Undecided } \\
(n=995, \\
53 \%)\end{array}$} & \multirow[b]{2}{*}{$p$} \\
\hline & & $n$ & $\%$ & $n$ & $\%$ & $n$ & $\%$ & \\
\hline Age & & & & & & & & $0.976^{\mathrm{b}}$ \\
\hline 30 s or younger & 219 & 55 & 14.1 & 62 & 12.6 & 102 & 10.3 & \\
\hline $40 \mathrm{~s}$ & 727 & 141 & 36.2 & 185 & 37.6 & 401 & 40.3 & \\
\hline $50 \mathrm{~s}$ & 734 & 141 & 36.2 & 194 & 39.4 & 399 & 40.1 & \\
\hline 60 s or older & 197 & 53 & 13.5 & 51 & 10.4 & 93 & 9.3 & \\
\hline Education & & & & & & & & $0.299^{\mathrm{b}}$ \\
\hline High school or lower & 350 & 71 & 18.2 & 88 & 17.9 & 191 & 19.2 & \\
\hline Vocational school & 188 & 29 & 7.4 & 57 & 11.6 & 102 & 10.3 & \\
\hline Junior college & 73 & 14 & 3.6 & 20 & 4.1 & 39 & 3.9 & \\
\hline University & 1100 & 236 & 60.5 & 289 & 58.7 & 575 & 57.8 & \\
\hline Graduate school & 166 & 40 & 10.3 & 38 & 7.7 & 88 & 8.8 & \\
\hline Marital status & & & & & & & & $0.180^{\mathrm{a}}$ \\
\hline Single & 319 & 72 & 18.5 & 73 & 14.8 & 174 & 17.5 & \\
\hline Married & 1432 & 289 & 74.1 & 378 & 76.9 & 765 & 76.9 & \\
\hline Widowed or divorced & 126 & 29 & 7.4 & 41 & 8.3 & 56 & 5.6 & \\
\hline Children & & & & & & & & $0.973^{\mathrm{a}}$ \\
\hline Yes & 1299 & 268 & 68.7 & 341 & 69.3 & 690 & 69.3 & \\
\hline No & 578 & 122 & 31.3 & 151 & 30.7 & 305 & 30.7 & \\
\hline Job description & & & & & & & & $0.001^{* a}$ \\
\hline Senior advisors/presidents & 541 & 104 & 26.7 & 174 & 35.4 & 263 & 26.4 & \\
\hline Directors & 319 & 88 & 22.6 & 83 & 16.9 & 148 & 14.9 & \\
\hline $\begin{array}{l}\text { Branch managers/section } \\
\text { chiefs }\end{array}$ & 1017 & 198 & 50.7 & 235 & 47.7 & 584 & 58.7 & \\
\hline Length of service & & & & & & & & $0.009^{* \mathrm{~b}}$ \\
\hline Less than 10 years & 544 & 121 & 31.1 & 162 & 32.9 & 261 & 26.2 & \\
\hline 10-20 years & 571 & 123 & 31.5 & 146 & 29.7 & 302 & 30.4 & \\
\hline $20-30$ years & 518 & 96 & 24.6 & 129 & 26.2 & 293 & 29.4 & \\
\hline 30 years or more & 244 & 50 & 12.8 & 55 & 11.2 & 139 & 14.0 & \\
\hline Sales results & & & & & & & & $0.001 * \mathrm{~b}$ \\
\hline Good & 304 & 87 & 22.3 & 73 & 14.9 & 144 & 14.5 & \\
\hline Moderate & 911 & 213 & 54.6 & 226 & 45.9 & 472 & 47.4 & \\
\hline Bad & 473 & 66 & 16.9 & 157 & 31.9 & 250 & 25.1 & \\
\hline Unclear & 189 & 24 & 6.2 & 36 & 7.3 & 129 & 13.0 & \\
\hline
\end{tabular}




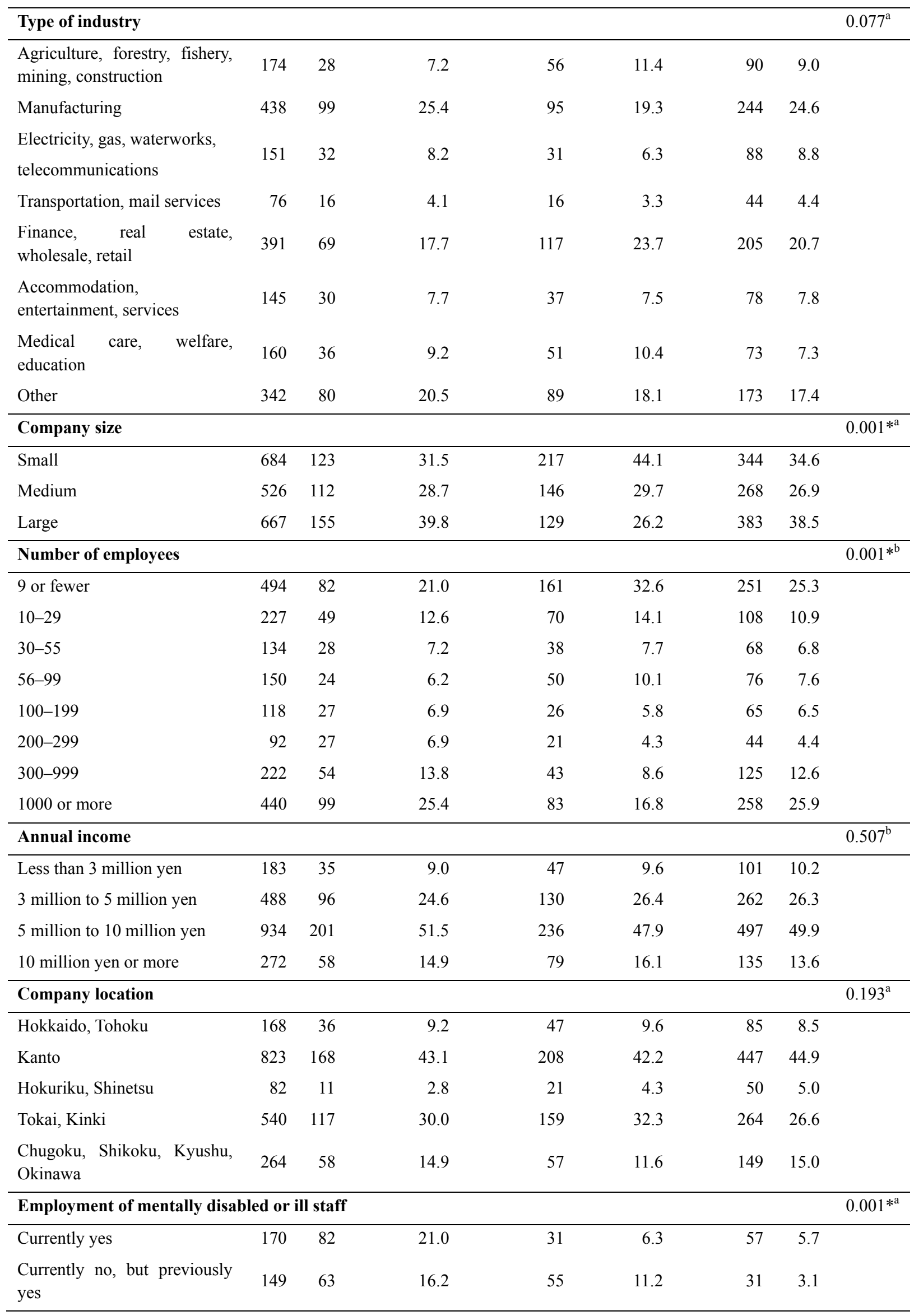




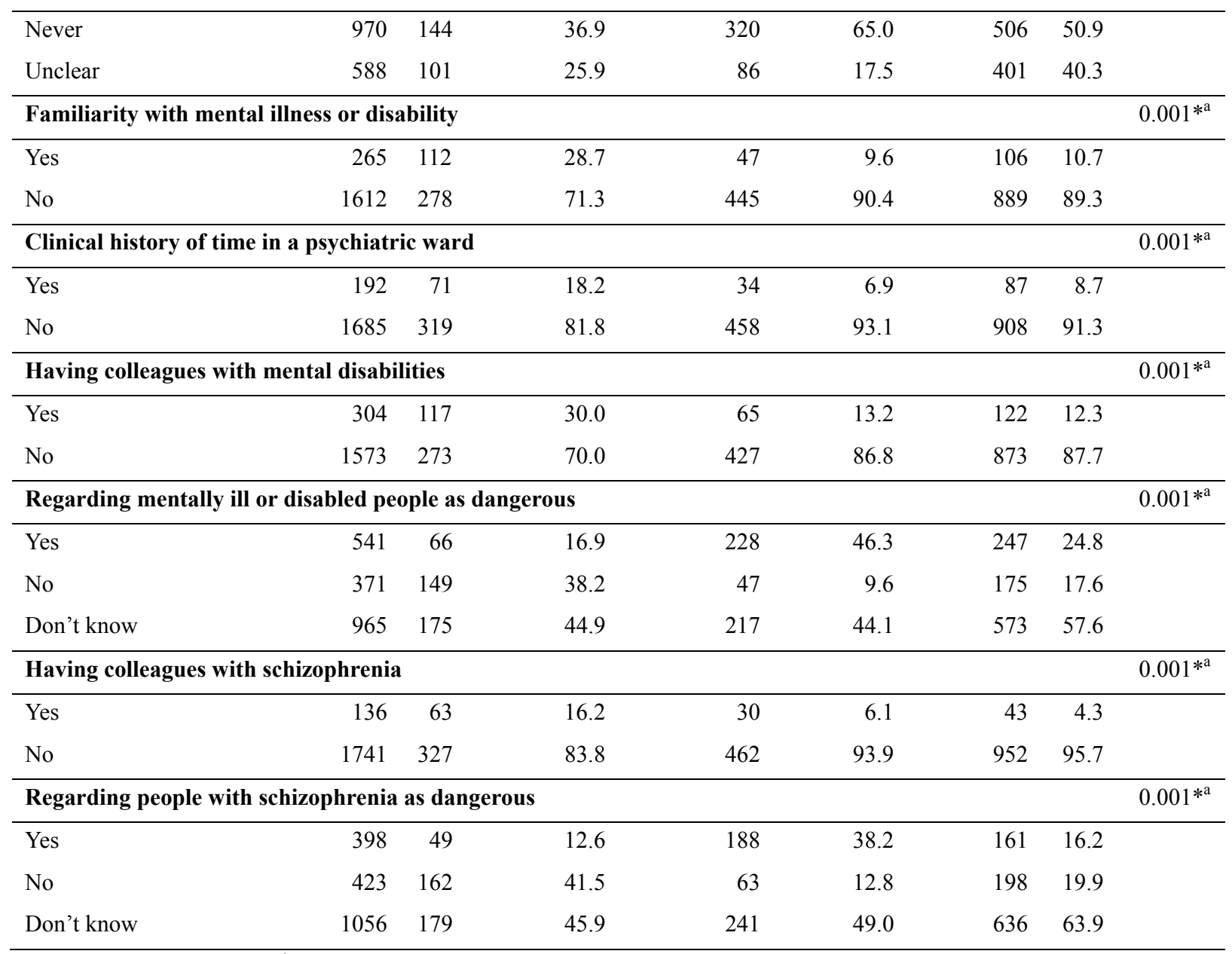

${ }^{\mathrm{a}}$ Pearson's chi-square test; ${ }^{\mathrm{b}}$ Kruskal-Wallis test; ${ }^{*} p<0.05$.

\subsection{Knowledge and Attitudes about Schizophrenia}

A comparison of the three groups (may employ, would not employ, undecided) showed that the mean \pm SD BKS and KIDI scores were highest in the "may employ" group (10.34 \pm 1.63 vs $68.17 \pm 16.62$; one-way analysis of variance; $\mathrm{p}<0.05 ; F=7.618, d f=2$ vs $F=3.803, d f=2$ ) (Table 2). The mean total SDSJ, WSDS, and DDM scores were highest in the "would not employ" group $(13.88 \pm 4.12,13.10 \pm 4.08$, and $32.78 \pm 4.81$; one-way analysis of variance; $\mathrm{p}=0.001 ; F=119.905, d f=2, F=99.411, d f=2$, and $F=23.53, d f=2$ ).

Table 2. Awareness of schizophrenia in each group $(N=1877)$

\begin{tabular}{lllll}
\hline & $\begin{array}{l}\text { "May employ" } \\
(\boldsymbol{n}=\mathbf{3 9 0}, \mathbf{2 0 . 8} \%)\end{array}$ & $\begin{array}{c}\text { "Would not employ" } \\
(\boldsymbol{n}=\mathbf{4 9 2}, \mathbf{2 6 . 2} \%)\end{array}$ & $\begin{array}{c}\text { "Undecided" } \\
(\boldsymbol{n}=\mathbf{9 9 5}, \mathbf{5 3} \%)\end{array}$ & $\boldsymbol{P}$ \\
\cline { 2 - 4 } & Mean \pm SD & Mean \pm SD & Mean \pm SD & $0.001^{*}$ \\
\hline BKS & $10.34 \pm 1.63$ & $9.97 \pm 1.44$ & $10.09 \pm 1.30$ & $0.022^{*}$ \\
KIDI & $68.17 \pm 16.62$ & $66.12 \pm 15.58$ & $65.52 \pm 16.11$ & $0.001^{*}$ \\
SDSJ & $10.14 \pm 3.66$ & $13.88 \pm 4.12$ & $11.47 \pm 3.50$ & $0.001^{*}$ \\
WSDS & $9.82 \pm 3.65$ & $13.10 \pm 4.08$ & $10.77 \pm 3.47$ & $0.001^{*}$ \\
DDM & $31.09 \pm 4.20$ & $32.78 \pm 4.81$ & $31.27 \pm 4.14$ & 0 \\
\hline
\end{tabular}

BKS = Basic Knowledge of Schizophrenia Scale, KIDI = Knowledge of Illness and Drugs Inventory,

SDSJ = Social Distance Scale-Japanese version, WSDS = Workplace Social Distance Scale,

$\mathrm{DDM}=$ Devaluation-Discrimination Measure; One-way analysis of variance, ${ }^{*}$ p-values $<0.05$. 


\subsection{Familiarity with Employment Support for People with Mental Illnesses}

Employers were most familiar with "support services provided by specialized staff in public employment security offices" (16.5\%) (Table 3). Overall, however, more than $83.5 \%$ of employers were unaware of the types of employment support available. A total of $40.4 \%$ of the employers said that they would value "consistent support from outside agencies in the form of advice and aid to support recruitment and ongoing employment" (Table 4). Large proportions also wanted "better knowledge and understanding about the employment of those with mental disabilities within the company" and "sufficient provision of grants at the time of recruitment".

Table 3. Familiarity with employment support for people with mental illness or disability

\begin{tabular}{|c|c|c|c|}
\hline \multirow{2}{*}{\multicolumn{2}{|c|}{ Type of employment support }} & \multicolumn{2}{|c|}{ Rated as aware } \\
\hline & & \multirow{2}{*}{$\begin{array}{l}\boldsymbol{n} \\
310\end{array}$} & \multirow{2}{*}{$\begin{array}{l}\% \\
16.5\end{array}$} \\
\hline 1 & $\begin{array}{l}\text { Support services provided by specialized staff in public employment security offices ("Total } \\
\text { support for the employment of people with mental disabilities") }\end{array}$ & & \\
\hline 2 & "Step-up" employment "bonus" for employing someone with a mental disability & 246 & 13.1 \\
\hline 3 & Job security bonus for employing someone with a mental disability & 303 & 16.1 \\
\hline 4 & Support services for hiring and reinstating disabled people, provided by local vocational centers & 241 & 12.8 \\
\hline 5 & Grant for employment development of special job seekers & 218 & 11.6 \\
\hline 6 & Trial employment grant & 252 & 13.4 \\
\hline 7 & Placement of job coaches & 179 & 9.5 \\
\hline 8 & Grant for employers engaged in Workplace Aid & 231 & 12.3 \\
\hline 9 & Support services for placing assistants in workplaces (grant for caregivers at work, etc.) & 134 & 7.1 \\
\hline 10 & $\begin{array}{l}\text { Grants other than those cited in } 9 \text { above, based on disabled people (commission of doctors for } \\
\text { health consultation, etc.) }\end{array}$ & 109 & 5.8 \\
\hline 11 & $\begin{array}{l}\text { Participation in promotional seminars about the employment of people with a mental disability, } \\
\text { organized by public employment security offices, etc. }\end{array}$ & 173 & 9.2 \\
\hline 12 & $\begin{array}{l}\text { Guidebooks and collections of good examples such as "Good practice in workplace improvement } \\
\text { for people with mental disabilities", etc. }\end{array}$ & 170 & 9.1 \\
\hline
\end{tabular}

Table 4. Support required to employ people with mental illnesses or disabilities

\begin{tabular}{|c|c|c|c|}
\hline \multirow{2}{*}{\multicolumn{2}{|c|}{ Type of employment support required }} & \multicolumn{2}{|c|}{ Rated as desired } \\
\hline & & \multirow{2}{*}{$\begin{array}{l}n \\
759\end{array}$} & \multirow{2}{*}{$\begin{array}{l}\% \\
40.4\end{array}$} \\
\hline 1 & $\begin{array}{l}\text { Consistent support from outside agencies, in the form of advice and aid to support recruitment and } \\
\text { ongoing employment }\end{array}$ & & \\
\hline 2 & Sufficient provision of grants at the time of recruitment & 519 & 27.7 \\
\hline 3 & Sufficient provision of grants to enable ongoing employment & 506 & 27.0 \\
\hline 4 & Sufficient human support such as job coaches and caregivers at work from recruitment onwards & 411 & 21.9 \\
\hline 5 & Grants to support both initial recruitment and ongoing employment & 367 & 19.6 \\
\hline 6 & $\begin{array}{l}\text { Promotion of knowledge and understanding about the employment of people with mental } \\
\text { disabilities within the company }\end{array}$ & 532 & 28.3 \\
\hline 7 & $\begin{array}{l}\text { Provision of information about individual disabilities and important notices in employment } \\
\text { management of each disabled person recruited }\end{array}$ & 356 & 19.0 \\
\hline 8 & $\begin{array}{l}\text { Provision of case studies of employment, and information about individual disabilities and } \\
\text { important notices in employment management }\end{array}$ & 353 & 18.8 \\
\hline 9 & Provision of information about the current support system & 294 & 15.7 \\
\hline 10 & $\begin{array}{l}\text { I would not want to employ mentally disabled or mentally ill people even if support systems were } \\
\text { well established and information was widely available }\end{array}$ & 465 & 24.8 \\
\hline
\end{tabular}




\section{Discussion}

We were able to identify characteristics of employers who believed that it was not possible to employ schizophrenia patients, which will improve the targeting of interventions. This group comprised, in particular, small-scale entrepreneurs who saw people with mental illnesses, including schizophrenia, as dangerous and who had no experience of contact with them. The mean \pm SD BKS scores for schizophrenia patients being dangerous were significantly higher for the "may employ" group than for the "would not employ" group (10.34 \pm 1.63 vs. $9.97 \pm 1.44 ; \mathrm{p}=0.001)$. This suggests that it is important to provide information to increase employers' willingness to recruit these individuals (Table 2). Statistics from the Japanese Ministry of Health, Labour and Welfare (Dec 10, 2017) show that employment is much lower among people with mental illnesses than among those with physical disabilities $(0.7 \%$ vs. $19.3 \%)$. Opportunities for contact with people with mental health problems in the workplace are therefore likely to be very limited. Beginning in 2018, enterprises with 50 or more employees will have to employ people with mental illnesses in Japan (Ministry of Health, Labour and Welfare, Dec 10, 2017), but those with fewer than 50 workers will be exempt from this requirement. Unless other measures are taken, small-scale employers may therefore continue to avoid recruiting schizophrenia patients; this measure may also explain why this group was less well informed than were those working in larger companies in the current study.

Stigma and social distance are almost synonymous (Chan, Mak \& Law, 2009). In our study, attitude scores (SDSJ, WSDS, DDM) were higher among those in the group unwilling to employ schizophrenia patients and lower in the "may employ" group (Table 2). In a number of surveys, employers have expressed negative attitudes about employing people with mental illnesses (Ozawa \& Yaeda, 2007; Stuart H, 2007). Employer attitudes and unwelcome corporate cultures reflecting stigma and prejudice against mental illness may constrain employment opportunities for this group (Dixon, Kruse, \& Van Horn, 2003; Domzal, Houtenville, \& Sharma, 2008; Schur, Kruse, \& Blanck, 2005). To avoid stigma, people with mental illnesses may try to continue to work despite having symptoms, and the majority do not seek help (Zhang, Rost, Fortney, \& Smith, 1999). There is evidence that stigma is one of the factors that hinders the employment of people with mental illnesses (Gaebel et al., 2008) because they fear having to disclose their illness (See Me Scotland, 2006; Yoshii, 2014). This may be because they were previously turned down for a job, dismissed, demoted, shunned, or harassed by co-workers after disclosure (Wahl, 1999a, 1999b). In our study, high scores on social distance and stigma were associated with lower likelihood of hiring schizophrenia patients, and low scores for these variables were associated with a greater likelihood of employment. It may therefore make sense to focus on strategies to reduce stigma among employers. One study found that schizophrenia patients with post-secondary or higher education had higher quality of life than those with secondary or lower education (Choo, Chew, Ho, \& Ho, 2017). To help schizophrenia patients acquire new working skills, it is important for the government to offer them training and provide further education.

This research also showed that employers have poor knowledge about employment support systems for those with mental illnesses (Table 3). One of the educational activities currently used in Japan to promote understanding of the need to employ people with mental illnesses is providing information about the experiences of working people with mental illnesses. This draws on and develops a model from 2009-2010, when measures to promote the employment of people with mental illnesses were left to companies without enough experience of employing such workers. Since 2011, collections of illustrative cases of the employment of workers with mental illnesses have been published, and seminars have been held throughout Japan. The Japan Organization for Employment of the Elderly, Persons with Disabilities and Job Seekers collects good practice techniques and research results, compiles guidebooks on job development, and distributes these materials to companies to familiarize them with employment support and management tips. However, this study has shown that employers still do not have sufficient knowledge about employment support systems for those with mental illnesses, suggesting that further outreach is needed.

Although people with schizophrenia may not be employed, they often wish to work and may be able to help mitigate future labor shortages. Continued efforts to combat low employment rates and barriers to employment among those with schizophrenia are valuable from a variety of perspectives. It is hoped that there will be greater opportunities in the future for people with schizophrenia to work.

\section{Acknowledgments}

The authors thank the study participants. This work was supported by a 2017 Health Science Center (1606000852) entitled Investigations of the Consciousness of Employers Concerning Schizophrenia and the Development of Educational Enlightenment Media. 


\section{Competing Interests Statement}

On behalf of all authors, the corresponding author states that there is no conflict of interest.

\section{References}

Ali, M., Schur, L., \& Blanck, P. (2011). What types of jobs do people with disabilities want? Journal of Occupational Rehabilitation, 21(2), 199-210. https://doi.org/10.1007/s10926-010-9266-0

Cabinet Office, Government of Japan (2013). White paper on persons with disabilities [In Japanese]. Retrieved from http://www8.cao.go.jp/shougai/whitepaper/h25hakusho/gaiyou/h1_01.html

Chan, J. Y., Mak, W. W., \& Law, L. S. (2009). Combining education and video-based contact to reduce stigma of mental illness: "The Same or Not the Same" anti-stigma program for secondary schools in Hong Kong. Social Science and Medicine, 68(8), 1521-1526. https://doi.org/10.1016/j.socscimed.2009.02.016

Choo, C.C., Chew, P. K. H., Ho, C. S., \& Ho, R. C. (2017). Prediction of quality of life in Asian patients with schizophrenia: a cross-sectional pilot study. Front Psychiatry, 8, 198. https://doi.org/10.3389/ fpsyt.2017.00198

Corrigan, P. W., Kuwabara, S., Tsang, H., Shi, K., Larson, J., Lam, C. S., \& Jin, S. (2008). Disability and work-related attitudes in employers from Beijing, Chicago, and Hong Kong. International Journal of Rehabilitation Research, 31(4), 347-350. https://doi.org/10.1097/MRR.0b013e3282fb7d61

Dalgin, R. S., \& Bellini, J. (2008). Invisible disability disclosure in an employment interview: impact on employers' hiring decisions and views of employability. Rehabilitation Counseling Bulletin, 52(1), 6-15. https://doi.org/10.1177/0034355207311311

Dightman, C. R., \& Marks, J. B. (1968). Employer attitudes toward the employment of the ex-psychiatric patient. Mental Hygiene 52(4), 562-569.

Dixon, K., Kruse, K., \& Van Horn, C. (2003). Restricted access: a survey of employers about people with disabilities and lowering barriers to work. John J Heldrich Center for Workforce Development, Rutgers University, New Brunswick. Retrieved from https:/smlr.rutgers.edu/sites/default/files/documents/ Heldrich\%20disability\%20survey\%20report.pdf

Domzal, C., Houtenville, A., \& Sharma, R. (2008). Survey of employer perspectives on the employment of people with disabilities: Technical Report. Prepared under contract to the Office of Disability and Employment Policy, U.S. Department of Labor. CESSI, McLean, VA. Retrieved from https://icdr.acl.gov/ system/files/resources/survey_report_jan_09.pdf

Gaebel, W., Zaske, H., Baumann, A. E., Klosterkötter, J., Maier, W., Decker, P., \& Moller, H.-J. (2008). Evaluation of the German WPA "Program against stigma and discrimination because of schizophrenia-Open the Doors": results from representative telephone surveys before and after three years of anti-stigma interventions. Schizophrenia Research, 98, 184-193. https://doi.org/10.1016/j.schres.2007.09.013

Hand, C. \& Tryssenaar, J. (2006). Small business employers' views on hiring individuals with mental illness. Psychiatric Rehabilitation Journal, 29(3), 166-173. http://dx.doi.org/10.2975/29.2006.166.173

Ho, R.C., Mak, K.K., Chua, A.N., Ho, C.S., \& Mak, A. (2013). The effect of severity of depressive disorder on economic burden in a university hospital in Singapore. Expert Rev Pharmacoecon Outcomes Res, 13(4), 549-559. PMID: 23977979

Liberman, R. P. (1998). Skills training versus psychosocial occupational therapy for persons with persistent schizophrenia. American Journal of Psychiatry, 155(8), 1087-1091. http://dx.doi.org/10.1176/ajp.155.8.1087

Link, B. G. (1987). Understanding labelling effects in the area of mental disorders: an assessment of the effects of expectations of rejection. American Sociolological Review, 52, 96-112. http://dx.doi.org/10.2307/2095395

Maeda, S., Ochiai, M., Renri, T., Aga, J., \& Mukasa, H. (1994). Research of the results of Knowledge of Illness and Drugs Inventory (KIDI) toward schizophrenia and the patients' family [in Japanese]. Japanese Bulletin of Social Psychiatry, 2, 173-174.

Ministry of Foreign Affairs of Japan. (2017). Convention on the rig-ts of persons with disabilities [In Japanese]. Retrieved from http:/www.mofa.go.jp/mofaj/gaiko/jinken/index_shogaisha.html

Ministry of Health, Labour and Welfare. (2017). Results regarding the employment situation of persons with disabilities in 2017 [In Japanese]. Retrieved from http://www.mhlw.go.jp/stf/houdou/0000105446.html 
Ministry of Health, Labour and Welfare. (2017). Employment rate system for persons with disabilities [In Japanese]. Retrieved from http://www.mhlw.go.jp/file/04-Houdouhappyou-11704000-Shokugyouanteikyok ukoureishougaikoyoutaisakubu-shougaishakoyoutaisakuka/0000084782_1.pdf

National Institute of Vocational Rehabilitation, Japan Organization for Employment of the Elderly, Persons with Disabilities and Job Seekers (2010). Research into mentally disabled people's working situations for the purpose of employment promotion (Research Paper No.95) Summary [In Japanese]. Retrieved from http://www.nivr.jeed.or.jp/download/houkoku/houkoku95.pdf

Olshansky, M. A., Grob, S., \& Malamud, I. T. (1958). Employers' attitudes and practices in the hiring of ex-mental patients. Mental Hygiene, 42, 391-401.

Ozawa, A., \& Yaeda, J. (2007). Employer attitudes toward employing persons with psychiatric disability in Japan. Journal of Vocational Rehabilitation, 26(2), 105-113.

Puri, B., Hall, A., \& Ho, R.C. (2014). Revision notes in psychiatry (3rd edition) CRC Press: Boca Raton. 352.

Schur, L., Kruse, D., \& Blanck, P. (2005). Corporate culture and the employment of persons with disabilities. Behavioral Sciences and the Law, 23, 3-20. http://dx.doi.org/10.1002/bsl.624

See Me Scotland (2006). See me so far: a review of the first four years of the Scottish Anti-Stigma Campaign. Scottish Executive. Retrieved from http://www.docs.csg.ed.ac.uk/EqualityDiversity/see_me_so_far.pdf

Stuart H. (2007). Employment equity and mental disability. Current Opinion in Psychiatry, 20(5), 486-490. http://dx.doi.org/0.1097/YCO.0b013e32826fb356

Tse, S. (2004). What do employers think about employing people with experience of mental illness in New Zealand workplaces? Work, 23(3), 267-274.

Wahl, O. (1999a). Mental health consumers' experience of stigma. Schizophrenia Bulletin, 25, 467-478. http://dx.doi.org/10.1093/oxfordjournals.schbul.a033394

Wahl, O. (1999b). Telling is risky business: mental health consumers confront stigma. Rutgers University Press, New Brunswick, 374-377. https://doi.org/10.1080/15487760108415440

Whatley, C. (1959). Social attitudes towards discharge mental patients. Social Problems, 6, 313-320. http://dx.doi.org/10.1525/sp.1959.6.4.03a00050

Yoshii, H. (2014). Reasons for workplace mental illness disclosure and non-disclosure in Japan. Health, 6(14), 1780-1789. http://dx.doi.org/10.4236/health.2014.614210

Yoshii, H., Mandai, N., Saito, H., \& Akazawa, K. (2015). Reliability and validity of the Workplace Social Distance Scale. Global Journal of Health Science, 7(3), 46-51. http://dx.doi.org/10.5539/gjhs.v7n3p46

Yoshii, H., Watanabe, Y., Kitamura, H., Chen, J., \& Akazawa, K. (2011). Effect of an education program on improving knowledge of schizophrenia among parents of junior and senior high school students in Japan. BMC Public Health, 11, 323. http://dx.doi.org/10.1186/1471-2458-11-323

Zhang, M., Rost, K., Fortney, J., \& Smith, G. R. (1999). A community study of depression treatment and employment earnings. Psychiatric Services, 50, 1209-1213. http://dx.doi.org/10.1176/ps.50.9.1209

\section{Copyrights}

Copyright for this article is retained by the author(s), with first publication rights granted to the journal.

This is an open-access article distributed under the terms and conditions of the Creative Commons Attribution license (http://creativecommons.org/licenses/by/4.0/). 